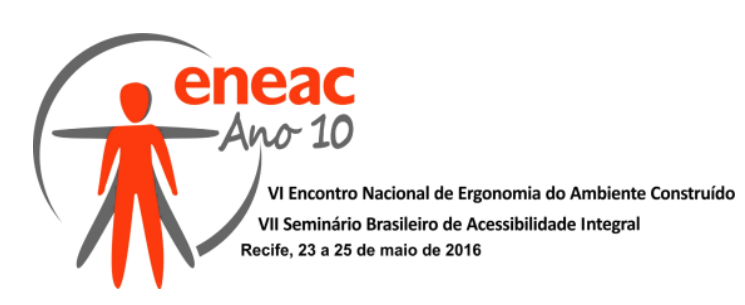

\title{
O JOGO DA ARQUITETURA: DISCUTINDO A ACESSIBILIDADE PARA SURDOS
}

\author{
FRANSOLIN, Liorne Cristina (1); \\ RODRIGUES, Júlio Cezar (2); \\ ANTONINI, Beatriz (3); \\ BERNARDI, Núbia (4) \\ KOWALTOWSKI, Doris C. C. Knatz (5)
}

(1) Arquiteta Urbanista

e-mail: liornef@gmail.com

(2) Arquiteto Urbanista

e-mail: julio rodrigues6@hotmail.com

(3) Arquiteta Urbanista

e-mail: bia.antonini.arq@gmail.com

(4) Faculdade de Engenharia Civil Arquitetura e Urbanismo, Doutora

e-mail: nubiab@fec.unicamp.br

(5) Faculdade de Engenharia Civil Arquitetura e Urbanismo, Profa. Titular

e-mail: doris@fec.unicamp.br

\begin{abstract}
RESUMO
A pessoa com deficiência auditiva vivencia diariamente algumas barreiras arquitetônicas que podem dificultar o processo de inclusão social, cultural e arquitetônico. Este artigo partiu da revisão da ABNT NBR 9050/ 2015 e do estudo realizado por Bauman (2010) sobre elaboração do projeto da residência dos estudantes da Gallaudet University - a primeira universidade para surdos. Para fomentar a inclusão foi elaborada uma dinâmica educativa para estudantes de arquitetura e arquitetos buscando repensar parâmetros arquitetônicos que de fato incluam a acessibilidade no partido de projeto, auxiliem o processo de projeto e promovam a interação do surdo com o ambiente construído.
\end{abstract}

Palavras chave: deficiência auditiva, acessibilidade, processo de projeto, parâmetros arquitetônicos, dinâmica educativa. 


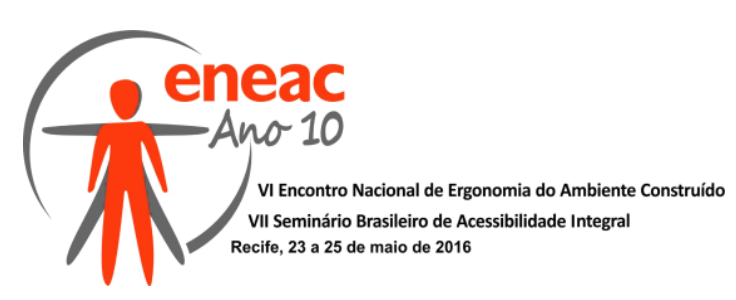

\begin{abstract}
A person with hearing disability experiences a few architectural barriers daily that may hinder the social, cultural and architectural process of inclusion. This article started by reviewing NBR 9050 (2015) and a study performed by Bauman(2010) on the project elaboration of Gallaudet University student residence, the first American university for the deaf founded in 1864. To foster inclusion, an educational game for students of architecture was elaborated seeking to rethink architectural parameters that facilitate the accessibility in the project concept, to assist the design process and to promote the deaf interaction with the built environment.
\end{abstract}

Keywords: hearing disability, accessibility, design process, architectural parameters, educational games.

\title{
1. INTRODUÇÃO
}

Aprendendo um novo método, o arquiteto estende sua linguagem e repertório de ferramentas para diferentes situações e problemas (LÖWGREN, STOLTERMAN, 1999).

Os surdos habitam um mundo sensorial onde o tato e a visão são o principal meio de comunicação e orientação espacial. Muitos utilizam a linguagem de sinais e mantém uma forte identidade cultural construída entorno desta sensibilidade, de experiências comuns e de vivências particulares. Frequentemente quando as pessoas surdas se reúnem, primeiramente reorganizam o mobiliário em um círculo de conversa, para permitir que todos tenham uma visão clara dos participantes com a finalidade de melhorar a integração e comunicação. Posteriormente ajustam as persianas e a iluminação, para otimizar a comunicação visual e reduzir a fatiga ocular. Os deficientes auditivos, muitas vezes fazem novas aberturas nas paredes, colocam espelhos e lâmpadas em lugares estratégicos para aumentar a consciência sensorial e manter a conexão visual entre as pessoas.

Organizar o ambiente físico é prática importante para as pessoas com deficiência auditiva. A falta da audição requer uma atenção redobrada na percepção visual dos acontecimentos no entorno periférico do próprio corpo (TYSIMBAL, 2010) e na organização do espaço físico que ocupa. Esta visibilidade tem por objetivo garantir segurança pessoal, prever e minimizar os riscos de acidentes, integrar o indivíduo em um mundo cada vez mais sonoro.

Vários estudos tem se debruçado sobre a questão do aprendizado cognitivo do deficiente auditivo, principalmente na área da pedagogia, mas ainda são poucos os estudos que apontam os caminhos para a discussão do espaço físico arquitetônico para este público. Daianese et al (2003) apontam uma pesquisa com a utilização de recursos computacionais e de Realidade Virtual como método de exploração de um ambiente construído buscando a visualização, imersão e interação como elemento facilitador para o aprendizado do deficiente auditivo. Nesta pesquisa são apontados procedimentos que utilizam imagens tridimensionais geradas pelo computador, com alto grau de realismo, para a execução de tarefas cotidianas através dos estímulos visuais e táteis. A finalidade é aumentar a cognição, contribuindo para uma melhor compreensão, apreensão e percepção da realidade física. 


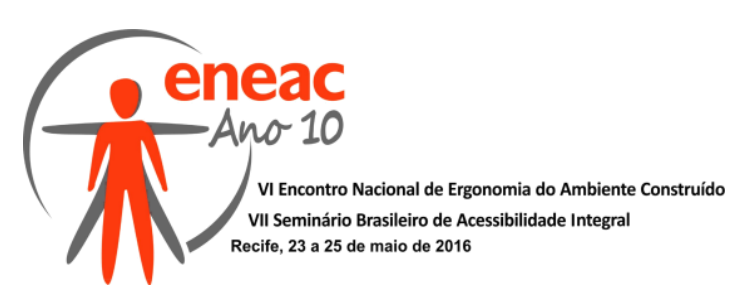

É de conhecimento na área da percepção ambiental os estudos de Hall (1977) sobre o campo da proxêmica (a ciência que estuda os modos como o espaço é usado enquanto forma de comunicação) e de Sommer (1969) sobre os conceitos de privacidade e espaço pessoal. Segundo Hall (1977) o aparelho sensorial do homem insere-se em duas categorias que podem ser classificadas em receptores à distância (aqueles que se relacionam com o exame de objetos distantes - os olhos, os ouvidos e o nariz) e receptores imediatos (os empregados para examinar o mundo de perto - o mundo do tato, as sensações que recebemos da pele, membranas e músculos). Segundo os conceitos de privacidade (SOMMER, 1969), cada indivíduo percebe, sente e atua em um ambiente conforme o seu ponto de vista, o que vai originar um espaço ao seu redor no qual ele está apto a agir com naturalidade e confiança. É neste mundo mais próximo que os surdos obtém grande parte de sua percepção que os ajudará a enfrentar os desafios colocados em um mundo de difícil inclusão.

No Brasil, o marco inicial do estudo do ambiente construído para surdos foi à versão revisada da ABNT NBR9050 - Acessibilidade a edificações mobiliário e espaços e equipamentos urbanos (2015) que propõe alguns acréscimos e adequações necessárias para atender os surdos e pessoas com baixa audição. Os critérios e parâmetros técnicos apresentados para a comunicação e informação dos surdos tem como referência a ABNT NBR10152 - Níveis de ruído para conforto acústico elucidando as três variáveis do som: frequência, intensidade e duração.

A ABNT NBR9050 orienta que haja um transmissor FM a cada $200 \mathrm{~m}^{2}$ de área para a comunicação e que os receptores devam ser compatíveis com os diferentes aparelhos auditivos. E como serviço de apoio ao surdo o acompanhamento de um intérprete de LIBRAS. O símbolo internacional das pessoas surdas ou com baixa audição deve ser adotado e utilizado em todos os locais onde as mesmas possam ter procedimentos ou serviços. Com relação ao mobiliário a norma recomenda que sejam acessíveis e que garantam as manobras e aproximações assim como as faixas de alcance manual, visual e auditivo.

Pelas referências e demais bibliografias consultadas, percebe-se a dificuldade em encontrar recomendações de intervenções e adequações físicas nas edificações, ou parâmetros para o projeto arquitetônico específico para surdos, refletindo a carência de literatura sobre o tema no Brasil.

Foram investigadas referências de outras localidades e destacou-se a metodologia do DeafSpace utilizada e aplicada por BAUMAN (2010) para elaboração do programa de necessidades do prédio dos Dormitórios da Gallaudet University em Washington D.C (HALES, 2013; O CONNEL, 2012) . Outra referência é Tysimbal (2010) que apresenta um estudo com aplicação dos conceitos do DeafSpace para escola primária em Rockville, Maryland, EUA. O desenvolvimento deste projeto considerou como conceitos a conectividade visual, a circulação, o estar coletivo e o sentimento de lar.

\subsection{A Metodologia DEAFSPACE}

Em 2005 o arquiteto Hansel Bauman iniciou o projeto DeafSpace (DSP) em parceria com a Gallaudet University, uma importante instituição educacional norte americana para surdos e pessoas com perda auditiva. Os preceitos fundamentais do DeafSpace estão baseados na consciência da linguagem gestual e na conectividade visual entre pessoas, no sentimento de segurança e bem estar, na clareza da circulação e dos percursos (TYSIMBAL, 2010). Outros princípios e conceitos trabalhados são: geometria circular, largura, coletividade, evitar pontos "cegos", transparências. 


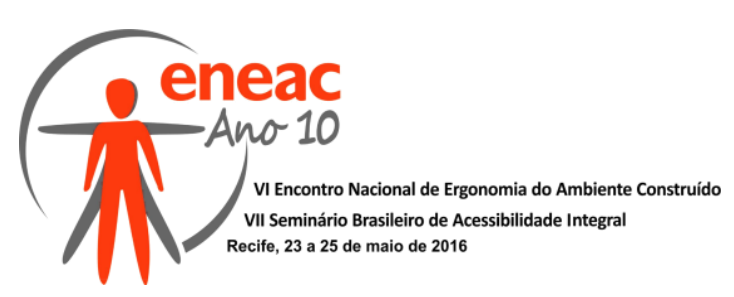

Bauman realizou uma série de cursos, análises de câmera de vídeo e entrevistas com alunos, professores e funcionários da Gallaudet Universtiy, o que resultou na produção de um documento com mais de 100 orientações construtivas, divididos em cinco preceitos necessários para as interações surdas no ambiente, tornando-se os Cinco Preceitos do Deaf Space (http://www.gallaudet.edu/campus-design/deafspace.html):

1. Alcance Sensorial: a orientação espacial e a consciência das atividades desenvolvidas dentro de um dado ambiente são essenciais para a promoção da sensação de bem estar e segurança. Os surdos "leem", as atividades no seu entorno que podem não ser imediatamente evidentes para muitos ouvintes, através de pistas visuais e táteis, tais como o movimento de sombras, vibrações, ou mesmo a leitura de mudanças na expressão e posição de outros ao seu redor. Muitos aspectos do ambiente construído podem ser projetados para facilitar a consciência espacial "em 360 graus" e facilitar a orientação e a mobilidade.

2. Espaço e Proximidade: com a finalidade de manter a comunicação visual clara os surdos ficam a uma distância que permite a visualização da expressão facial e o entorno dos seus interlocutores. O espaço entre dois surdos conversando tende a ser maior do que o existente em uma conversa falada. Este espaço necessário para comunicação entre os surdos afeta diretamente o layout do mobiliário e as dimensões do ambiente construído.

3.Mobilidade e proximidade: enquanto caminham juntos os surdos tendem a manter uma distância para a comunicação visual e alternar o olhar entre o interlocutor e seus arredores verificando riscos e mantendo a direção correta.

4. Luz e Cor: más condições de iluminação, tais como brilho, padrões de sombra e luz de fundo interrompem a comunicação visual e contribuem para a fadiga ocular, a perda de concentração e a exaustão física. A iluminação artificial adequada e elementos arquitetônicos para controlar a luminosidade do dia são soluções importantes para obter uma luz suave e difusa de acordo com as necessidades dos surdos. A cor pode ser usada para contrastar os tons de pele e realçar a linguagem de sinais.

5. Acústica e Interferências Eletromagnéticas: os surdos e as pessoas com dificuldades auditivas possuem diferentes níveis de audição e assim o som pode ser uma forma de distração, especialmente para pessoas que utilizam aparelhos auditivos de assistência ou possuem implantes cocleares. A reverberação causada por ondas sonoras que refletem em superfícies rígidas podem ser especialmente perturbadoras, ou mesmo dolorosa e assim os espaços devem ser concebidos para reduzir seus efeitos e os ruídos de fundo.

As diretrizes elaboradas por Bauman são determinantes para o desenvolvimento e estudos de ambientes amigáveis para as pessoas com deficiência auditiva. O presente artigo apresenta uma pesquisa em que se procurou discutir a acessibilidade para pessoas surdas. Após a revisão da literatura relacionada ao tema, os 5 Preceitos do DeafSpace foram aplicadas em uma dinâmica que envolveu arquitetos em diferentes estágios de experiências profissional e acadêmica. Foi desenvolvida uma dinâmica em forma de jogo onde se propõe a discussão de intervenções no projeto arquitetônico visando as necessidades das pessoas com diferentes graus de surdez. A ideia do jogo teve como proposta estimular a percepção dos projetistas para uma questão pouco valorizada: a relação da pessoa com deficiência auditiva com o ambiente construído e o seu entorno próximo.

\section{DESENVOLVIMENTO DA DINÂMICA}




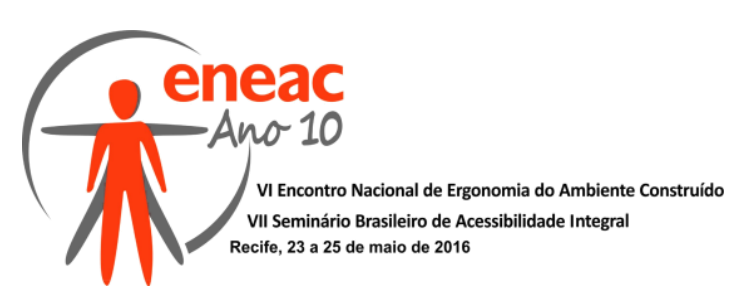

Na busca por um maior envolvimento dos projetistas, para ultrapassar os requisitos mínimos estabelecidos na NBR 9050, observou-se que uma dinâmica entre arquitetos e estudantes de arquitetura contribui para a comunicação e consolidação dos preceitos e parâmetros que contemplam acessibilidade. A inspiração para elaborar a dinâmica, aqui descrita, tem referência na metodologia de Bauman.

\subsection{Metodologia da Dinâmica}

A estrutura metodológica do jogo foi baseada nos 5 Preceitos do DeafSpace observados por Bauman (2010). O objetivo foi desenvolver um jogo que estimule a discussão sobre as necessidades espaciais de pessoas com deficiências auditivas. $\mathrm{O}$ jogo é direcionado à estudantes de arquitetura ou arquitetos, independente do seu tempo de formação acadêmica e profissional.

Os 5 preceitos foram traduzidas em cinco grupos de cartas, semelhantes as encontradas nos jogos de mesa, o que definiu a escolha dos naipes (Figuras 2 a 6), sendo eles: Alcance Sensorial (naipe vermelho), Espaço e Proximidade (naipe amarelo), Luz e Cor (naipe verde), Mobilidade e Proximidade (naipe azul), Acústica e Interferências Eletromagnéticas (naipe laranja). Cada naipe reúne algumas soluções e parâmetros arquitetônicos que exemplificam os preceitos do DeafSpace. As cartas foram diagramadas da seguinte maneira:

- $\quad$ Em cada carta foi colocada um título, uma definição, um ícone e a indicação do naipe, conforme apresentado na Figura 1;

- $\quad$ O título faz referência a um atributo arquitetônico diretamente relacionado ao respectivo naipe;

- Uma breve descrição do tipo de espaço desejado, ação, características ou conceito que o lugar deverá ter é relatado em definição;

- $\quad O$ ícone é representado por uma imagem modelo das características formais referenciando o conceito que o espaço deverá apresentar. É importante destacar que as imagens dos ícones das cartas foram reproduzidas de Bauman (2010; DKA, 2015);

- Os naipes estão indicados por cores e representam os 5 Preceitos do DeafSpace que deverão ser discutidos durante o jogo;

Figura 1. Estrutura das Cartas.

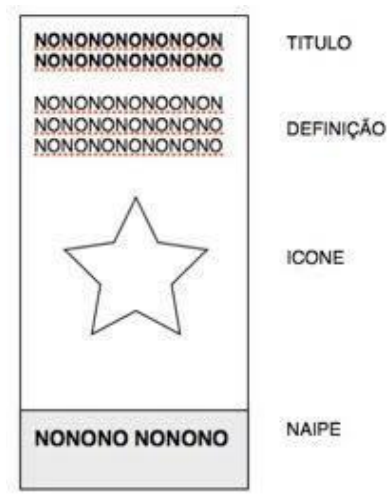

Fonte: Elaborado pelos autores. 


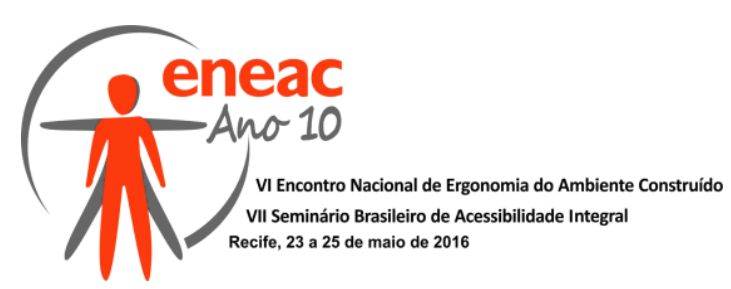

Figura 2. Naipe Alcance Sensorial.
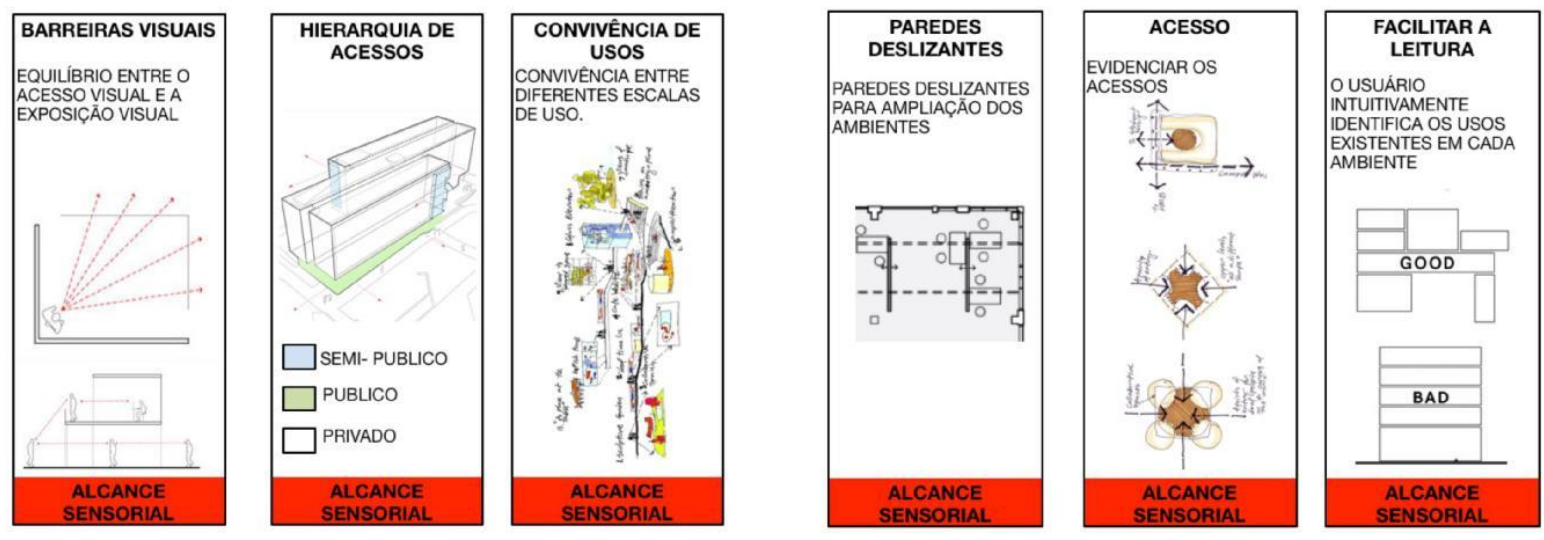

Fonte: Elaborado pelos autores

Figura 3. Naipe Espaço e Proximidade.
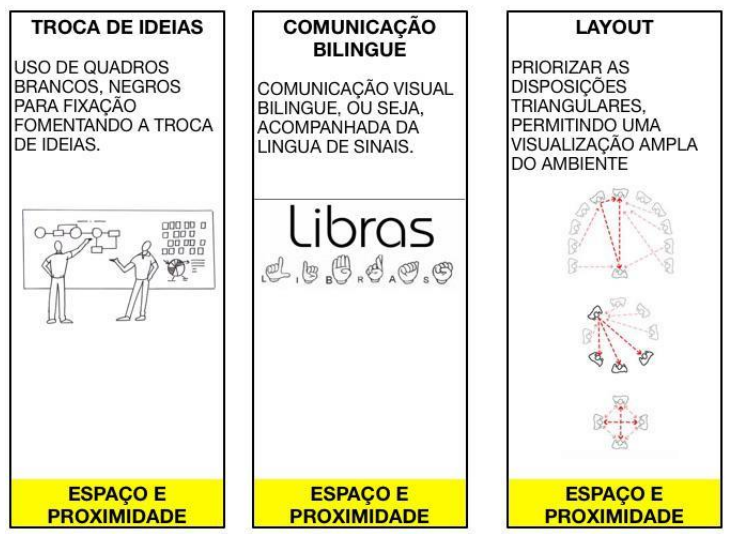

Fonte: Elaborado pelos autores.

Figura 4. Naipe Luz e Cor.

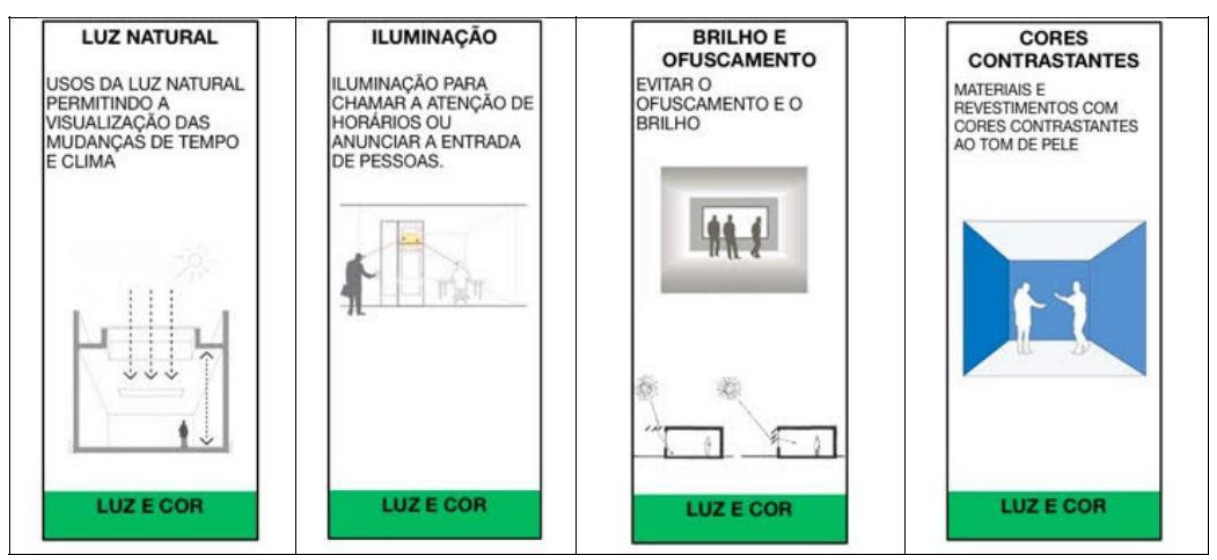

Fonte: Elaborado pelos autores. 


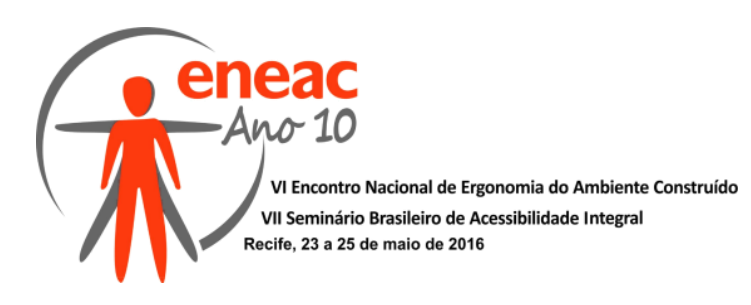

Figura 5. Naipe Mobilidade e Proximidade.

Figura 6. Naipe Acústica e Interferências Eletromagnéticas
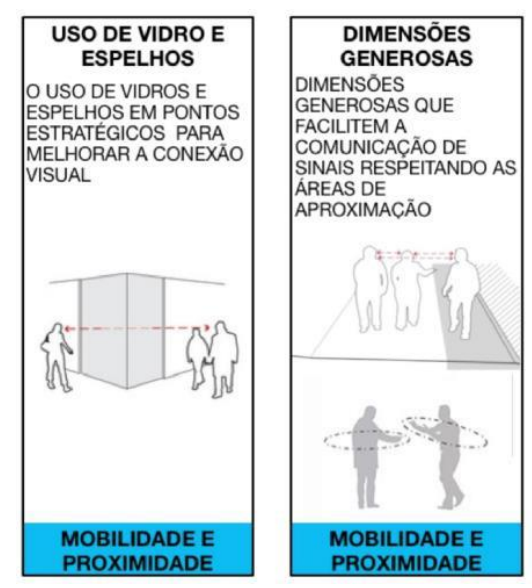

Fonte: Elaborado pelos autores

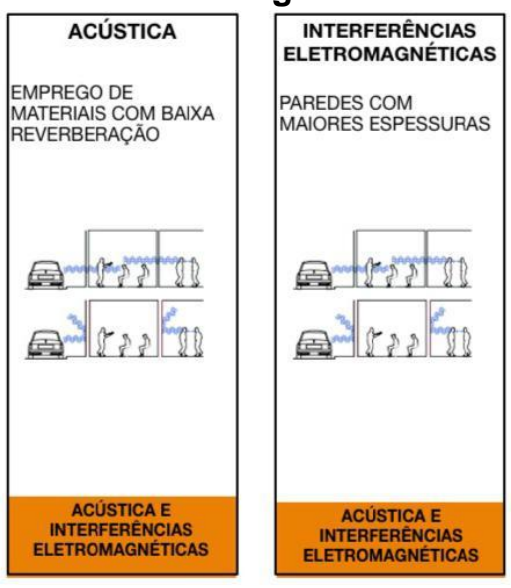

Fonte: Elaborado pelos autores

\subsection{Regras da Dinâmica}

As regras de cada etapa do jogo são apresentadas imediatamente antes do inicio da mesma.

- $\quad$ Primeira etapa: Os jogadores devem compor no mínimo três equipes de três a cinco arquitetos ou estudantes de arquitetura. Cada equipe recebe um jogo de cartas e um envelope. Os participantes devem manusear as cartas, uma vez que a troca de informações é decisiva para o sucesso da atividade devendo elencar a carta com a orientação construtiva mais importante e representativa de cada naipe no conjunto de cada preceito. No fechamento deste ciclo cada grupo terá cinco cartas, uma para cada preceito. O tempo previsto para realizar esta etapa é de dez minutos.

- $\quad$ Segunda etapa: Na sequência apresenta-se o projeto de um imóvel com um breve histórico e com uma planta baixa e fotos do local, além de material para desenho (Figura 7). Nessa etapa do jogo os envelopes das cartas escolhidas na primeira etapa devem ser trocados entre as equipes e cada equipe deverá fazer proposta de intervenção e adequação de acordo com as cartas contidas no envelope que receberam. O tempo previsto para realizar esta etapa é de quinze minutos.

- $\quad$ Terceira etapa: O croqui produzido, assim como a cartas utilizadas para a produção do croqui são encaminhadas para uma terceira equipe. Essa terceira equipe deverá fazer uma leitura das cartas e fazer uma leitura crítica do projeto verificando se as cartas escolhidas foram contempladas em projeto e devem elaborar uma critica construtiva sobre as soluções adotadas. O tempo para realizar esta etapa é de quinze minutos.

- Quarta etapa: a última etapa do jogo deve ser um "feedback" de todos os participantes expondo quais foram as dificuldades encontradas em cada etapa. Sejam elas de entendimento do conteúdo das cartas, de se elaborar uma proposta a partir deste conteúdo ou mesmo a compreensão da 


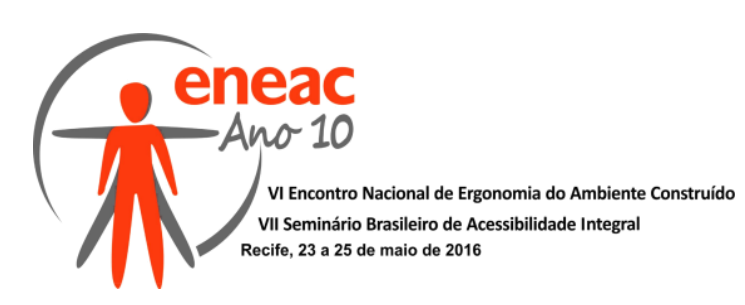

representação gráfica do croqui. O tempo para realizar esta etapa é de vinte minutos.

Figura 7. Material da dinâmica: foto do projeto a ser analisado, planta técnica do projeto (neste caso já com propostas de intervenção), conjunto de cartas/naipes, envelope.

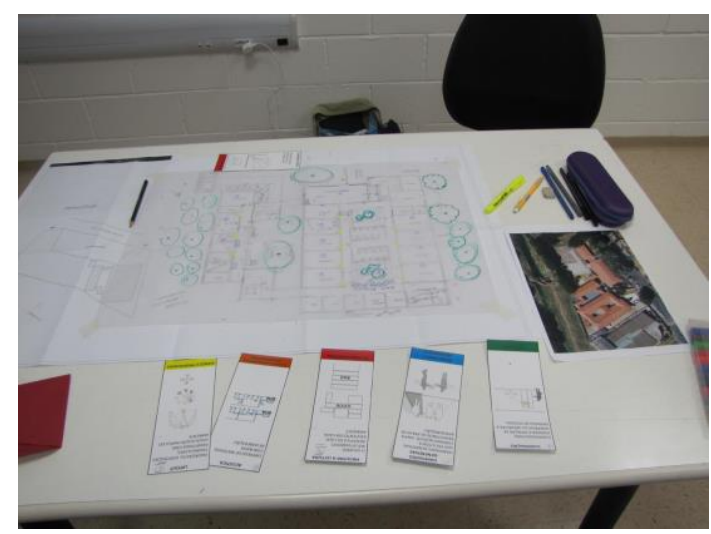

Fonte: foto dos autores.

\subsection{Aplicação da Dinâmica}

A dinâmica foi realizada com 9 participantes, sendo composto de três grupos com três participantes em cada um. O perfil dos jogadores era composto por estudantes da pós graduação e professores de arquitetura. Como proposta para a aplicação da segunda etapa foi apresentado o projeto e fotos de uma escola que atende crianças e adolescentes surdos na cidade de Campinas, Estado de São Paulo, o projeto e a construção foram realizados no final da década de oitenta e embora o edifício tenha sido concebido para abrigar a instituição, não há na arquitetura característica específica que promova a interação entre eles, com exceção da iluminação de comunicação que alerta para o início e término das atividades.

\subsection{Resultados da Dinâmica}

A dinâmica foi dividida em 3 Equipes com 3 integrantes cada. As considerações abaixo refletem o resultado de cada equipe, após a realização das três etapas iniciais (Figuras 8 e 9).

Figura 8 e 9. Imagens da dinâmica. (rostos dos participantes omitido para revisão cega). 

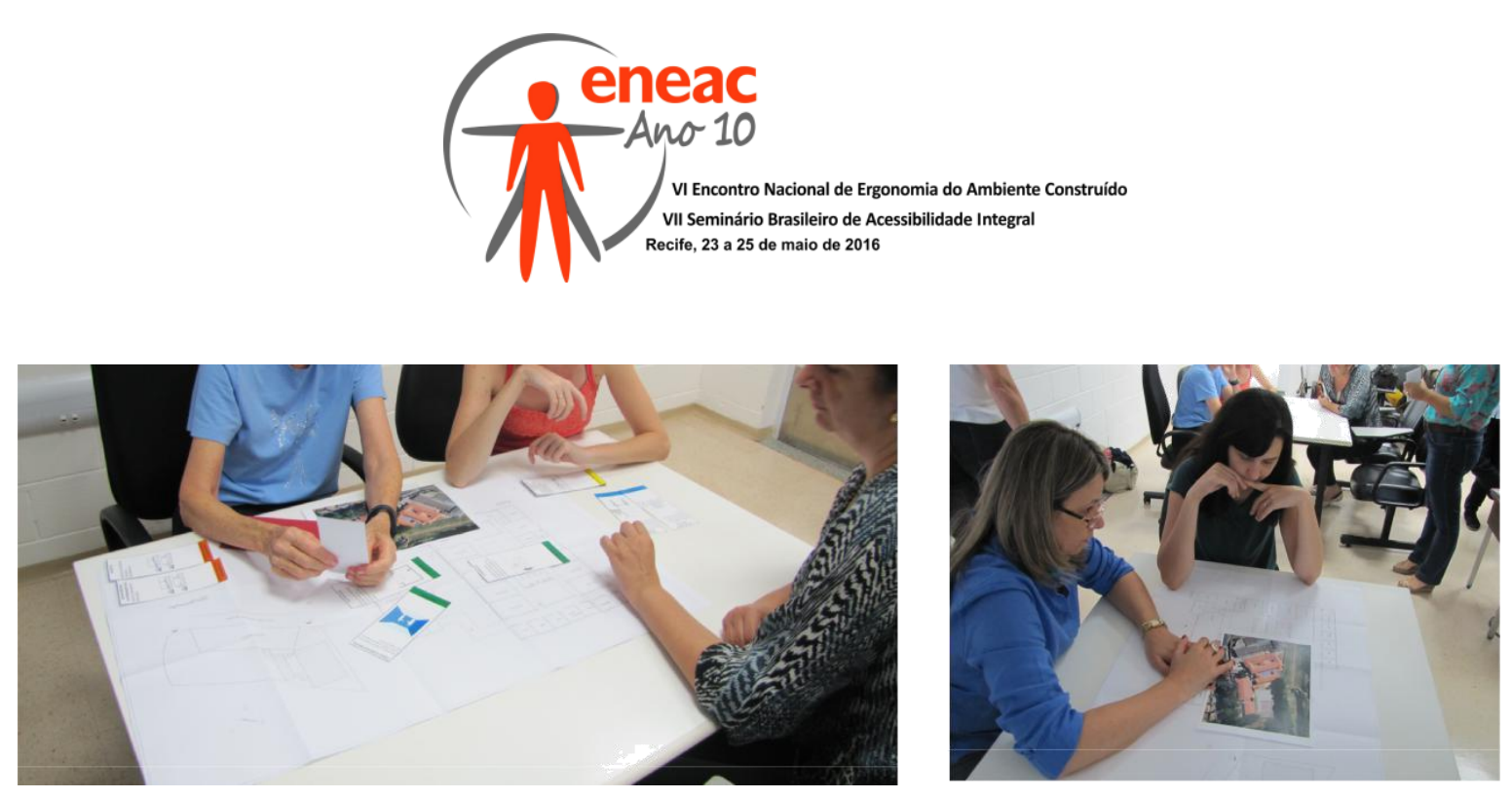

Fonte: Foto dos autores

A Equipe "A" ultrapassou os elementos priorizados nas cartas tendo uma forte preocupação com as questões de conforto térmico sendo possível verificar, pelas sugestões de ampliação das janelas da edificação, a possibilidade de implantar ventilação cruzada nas salas de aula e na administração, criar uma área com paisagismo sombreando as áreas de lazer e convívio e a utilização de brise-soleil nas fachadas com maior incidência solar. A Equipe "A" (Figura 10) trabalhou com todas as cartas recebidas propondo:

- Barreiras visuais - alteração do fluxo interno para melhor comunicação

- Dimensões generosas - ampliação a largura dos corredores de circulação

- Acústica - utilização de forros acústicos no refeitório e nas salas de aula

- Lay out - disposição das carteiras da sala de aula em círculo permitindo a visualização de todas as pessoas

- lluminação - utilização de pontos de iluminação para anunciar a entrada de pessoas e indicar eventos como por exemplo o intervalo entre as aulas.

- Facilitar a Leitura - criação de bancos (lugares de estar/leitura/descanso) no corredor entre a biblioteca, as salas de aula e o pátio.

A Equipe "B" foi a que demonstrou de forma mais clara o conceito das cartas na proposta, utilizando- se para isso de legenda de acordo com as cores dos naipes (Figura 9) . Esta estratégia possibilitou identificar rapidamente as propostas arquitetônicas para cada grupo de naipe. A Equipe "B" (Figura 11) trabalhou com todas as cartas recebidas propondo:

- Barreiras visuais - remodelação do layout das salas.

- Convivência de uso - sinalização das áreas de uso

- Iluminação - utilização de pontos de iluminação para anunciar a entrada de pessoas e indicar eventos como por exemplo o intervalo entre as aulas.

- Uso de vidros e espelhos - instalação de vidros nos vértices de maior circulação

- Trocas de ideias - instalação de quadro informativo e interativo na área de refeitório e circulação

- Acústica - instalação de revestimento acústico nas salas de aula

Figura 10. Proposta de intervenção da Equipe A.

Figura 11. Proposta de intervenção da Equipe B. 


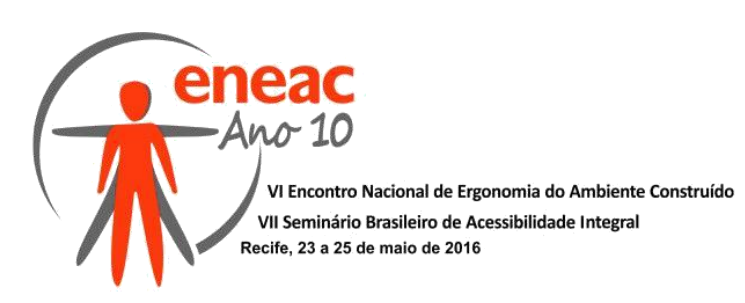

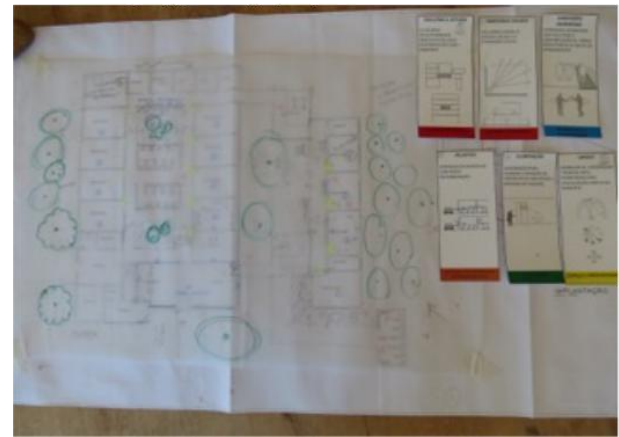

Fonte: Foto dos autores.

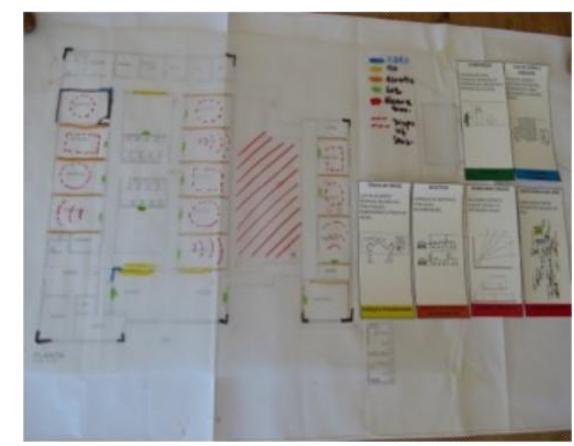

Fonte: Foto dos autores.

A Equipe "C" apresentou a maior intervenção física na edificação modificando usos de ambientes e propondo nova circulação interna (Figura 9), embora não tenha representado a carta de naipe espaço e proximidade. A Equipe "C" (Figura 12) apresentou a seguinte proposta:

- Acesso - evidenciar a entrada principal da escola a partir da própria arquitetura

- Uso de vidro e espelho - instalação de visores nas salas de aula para integrar interior/exterior

- Luz natural - instalação de uma janela na área da secretaria para facilitar a comunicação

- Acústica - utilização de material acústico nas salas de aula e refeitório.

- Barreiras visuais - demolição e alteração de usos possibilitando um maior acesso visual entre os pátios da escola.

Figura 12. Proposta de intervenção da Equipe C.

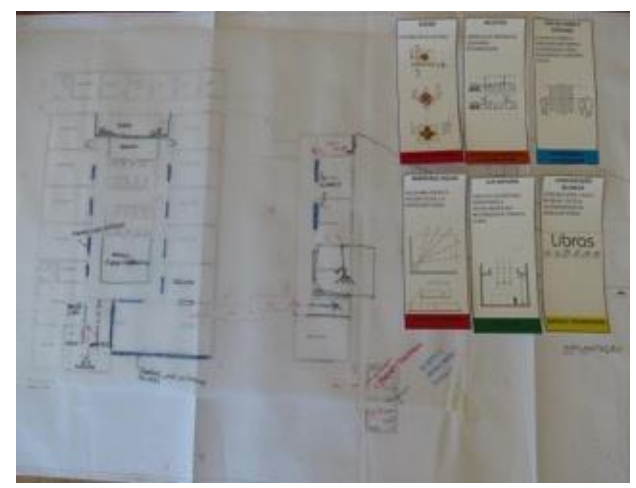

Fonte: Foto dos autores.

\subsection{Considerações sobre a Dinâmica}

$\mathrm{Na}$ aplicação da proposta foi estabelecido tempo para cada etapa, o que no desenvolvimento percebeu-se ser insuficiente, prejudicando alguns resultados que poderiam ter melhor qualidade. Foram encontradas dificuldades de compreensão de duas cartas, sendo elas Facilitar a Leitura e Convivência de Usos (ambas de naipe vermelho - Alcance 


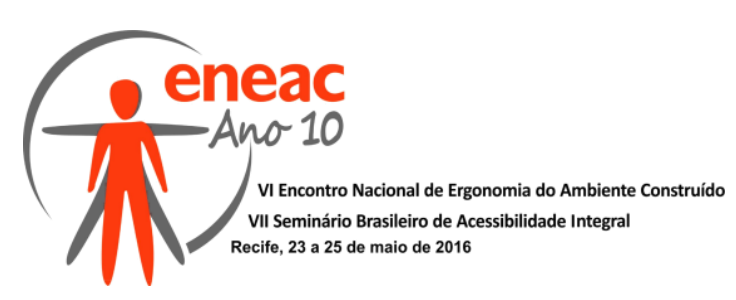

Sensorial) pela dificuldade de compreensão dos ícones. Outra questão relatada pelas equipes foi com relação a representação gráfica das propostas para a elaboração da defesa na terceira etapa do jogo.

O jogo gerou discussões interessantes sobre processo de projeto. Uma delas diz respeito a questão de novos aprendizados entre profissionais. A diversidade de compreensão do tema gera novos questionamentos que são compartilhados, podendo gerar e ampliar conceitos já estabelecidos em cada participante. A atividade pode contribuir para enriquecer o repertório projetual no momento de concepção do projeto.

O objetivo do jogo, apesar de ter sido aplicado uma única vez, obteve o resultado esperado e atingiu as expectativas da proposta. Pela dinâmica apresentada houve necessidade de todos estarem atentos a todas as cartas e todas as possibilidades de interferência que estas cartas apontavam no processo do projeto e possibilitou que todos os jogadores pudessem de alguma forma incorporar "novos" conceitos.

$\mathrm{Na}$ última etapa do jogo, onde os participantes teriam que defender as escolhas dos naipes juntamente com as intervenções arquitetônicas, observou-se que a de representação arquitetônica mais qualificada foi o que facilitou a compreensão e a defesa da proposta.

A questão da documentação e representação das soluções no desenvolvimento do projeto acessível não desempenhava um papel relevante inicialmente para a dinâmica, contudo ao longo da mesma demonstrou-se essencial. O projeto deve ser auto-explicativo, repassando informações para um terceiro de maneira objetiva, principalmente quando contemplar soluções pouco usuais, fruto de discussões pontuais ou específicas, evitando gerar interpretações equivocadas que comprometerão a qualidade do projeto.

\section{CONCLUSÃO}

As diretrizes e soluções arquitetônicas do DeafSpace foram pontuadas para a realidade de uma instituição educacional norte americana, tornando-se uma referência por sistematizar respostas para uma questão universal, a relação do surdo com o ambiente construído. Apropriar-se desse conhecimento e difundí-lo por meio de dinâmicas durante o processo de projeto proporciona uma reflexão que amplia a compreensão das possibilidades de projeto acessível e qualificado ultrapassando os critérios mínimos da legislação e normas nacionais.

A dinâmica, por ser formatada para projetistas, utilizou ferramentas mais visuais como cores, ícones e desenhos sendo esta característica elogiada pelos participantes que comentaram: "Quando estamos projetando é muito mais fácil ver uma imagem que sintetiza o assunto ou solução ao invés de ler um texto longo".

Outra observação interessante foi feita por um estudante de arquitetura que participou de uma outra ação onde todos os alunos tiveram de experimentar a limitação de mobilidade, utilizando cadeira de rodas, muletas, vendas e tampões de ouvido: "Este tipo de atividade (limitação de mobilidade) sensibiliza contudo não aumenta o repertório do projetista." Esta afirmação vai de encontro à afirmação de Bernardi \& Kowaltowski (2010) sobre a prática de exercícios de simulação e assimilação de outros papéis/personagens, também conhecidos como role-playing: é importante como sensibilização, porém não é suficiente para incorporação de todo o significado do corpo com alguma deficiência. É enriquecedor e mais efetivo combinar práticas diversas, inserindo principalmente os usuários e participantes com diferentes habilidades em dinâmicas que discutem o processo de projeto.

A dinâmica foi elaborada para uma atividade específica em sala de aula, para auxiliar o projetista nas fases iniciais do desenvolvimento do projeto tanto de novas edificações com 


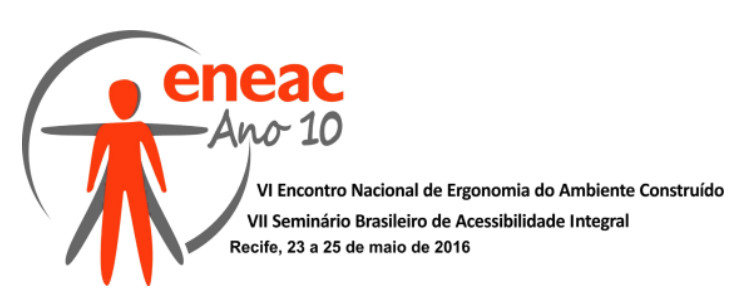

na adaptação de existente. Por ter sido aplicada uma única vez, necessita de ajustes e de maiores testes, contudo apontou aspectos interessantes.

Não é possível contentar-se com os critérios da legislação e simplesmente observar se o projeto está condizente com a mesma ou partir, exclusivamente, para a sensibilização sem demonstrar conhecimento das soluções propostas. Embora simples esta atividade, partiu de um contexto lúdico e ampliou o conhecimento e a reflexão principalmente em um campo pouco observado, o da acessibilidade para surdos.

\section{REFERÊNCIAS BIBLIOGRÁFICAS}

ABNT. Associação Brasileira de Norma Técnicas. NBR 9050/2004: Acessibilidade a edificações, mobiliários, espaços e equipamentos urbanos. Rio de Janeiro: ABNT, 2004. 97p.

ABNT. Associação Brasileira de Norma Técnicas. NBR 10152/1987: Níveis de ruído para conforto acústico. Rio de Janeiro: ABNT, 2004. 04p

BAUMAN, H. Deafspace Design Guideline, Working Draft. Washington, DC: Gallaudet University. 2010.

BERNARDI, N.: KOWALTOWSKI, D.C.C. K. When role playing is not enough: improved universal design education. Archnet-IJAR: International Journal of Architectural Research, v. 4, p. 376390, 2010.

DAIANESE, C. A.; GARBIN, T. R. G.; KIRNER, C . Sistema de Realidade Aumentada para Desenvolvimento Cognitivo da Criança Surda. In: Anais do 6th SBC Symposium on Virtual Reality, Ribeirão Preto, Brasil, 273-282, 2003.

DKA - Dangermond Keane Architecture. DeafSpace Design Guideline. Disponível em http://dangermondkeane.com/deafspace-design-guide Acesso em 01/11/2015

HALES, L. Clear Line of Sight - Faced with the ultimate universal design challenge, LTL Architects creates a new student center based on DeafSpace principles. METROPOLIS MAGAZINE/julyaugust, 2013. Disponível em: http://www.metropolismag.com/July-August-2013/Clear-Line-of-Sight/ Acesso em 01/10/2015.

HALL, E.T. A dimensão oculta. Trad. Sônia Coutinho. Rio de Janeiro: F. Alves, 1977. Cap.10. pp 105-114.

LÖWGREN, J.; STOLTERMAN, E. Design methodology and design practice. Methods \& tools, v. 6,.n. 1 , Jan/Feb. 1999. p. 13-20.

O'CONELL, K. A. Designing a City for the Deaf - A university in Washington, D.C., is developing a model for how urban spaces can better serve the deaf or hard of hearing. CITYLAB . Disponivel em http://www.citylab.com/design/2012/03/designing-city-deaf/1600/Acesso em 01/11/2015

SOMMER, R. Personal Space : the behavioral basis of design. New Jersey, Prentice-Hall Englewood Cliffs, 1969.

TYSIMBAL, K. A. Deaf space and the visual world - buildings that speak: an elementary school for the deaf. Thesis. School of Architecture Planning, and Preservation. Faculty of the Graduate School of the University of Maryland, College Park, EUA. 2010.

Link consultado: What is DeafSpace. Disponível em http://www.gallaudet.edu/campusdesign/deafspace.html Acesso em 01/11/2015. 